\title{
Identifying the Sources of Subsurface Contamination at the Hanford Site in Washington using High-Precision Uranium Isotopic Measurements
}

John N. Christensen ${ }^{1}$,

P. Evan Dresel ${ }^{2}$,

Mark E. Conrad ${ }^{1}$,

Kate Maher ${ }^{3}$, and

Donald J. DePaolo ${ }^{1,3}$

${ }^{1}$ Lawrence Berkeley National Laboratory

Center for Isotope Geochemistry

1 Cyclotron Rd., MS70A4429

Berkeley, CA 94720

2Pacific Northwest National Laboratory

MS K6-96,

Richland, WA, 99352

${ }^{3}$ Dept. of Earth and Planetary Science

University of California Berkeley

Berkeley, CA 94720 
In the mid-1990s, a groundwater plume of uranium (U) was detected in monitoring wells in the B-BX-BY Waste Management Area (WMA) at the Hanford Site in Washington. This area has been used since the late 1940s to store high-level radioactive waste and other products of U fuel-rod processing. Using multiple collector ICP source magnetic sector mass spectrometry (MC ICPMS) high precision uranium isotopic analyses were conducted of samples of vadose zone contamination and of groundwater. The ratios ${ }^{236} \mathrm{U} /{ }^{238} \mathrm{U},{ }^{234} \mathrm{U} /{ }^{238} \mathrm{U}$ and ${ }^{238} \mathrm{U} /{ }^{235} \mathrm{U}$ are used to distinguish contaminant sources. Based on the isotopic data, the source of the groundwater contamination appears to be related to a 1951 overflow event at tank BX-102 that spilled high level $\mathrm{U}$ waste into the vadose zone. The $\mathrm{U}$ isotopic variation of the groundwater plume is a result of mixing between contaminant $U$ from this spill and natural background $U$. Vadose zone $\mathrm{U}$ contamination at tank B-110 likely predates the recorded tank leak and can be ruled out as a source of groundwater contamination, based on the $U$ isotopic composition. The locus of vadose zone contamination is displaced from the initial locus of groundwater contamination, indicating that lateral migration in the vadose zone was at least 8 times greater than vertical migration. The time evolution of the groundwater plume suggests an average $U$ migration rate of $\sim 0.7-0.8 \mathrm{~m} /$ day showing slight retardation relative to a ground water flow of $\sim 1 \mathrm{~m} /$ day.

\section{Introduction}

Groundwater contamination at the Hanford Site, in south-central Washington, resulted from decades of nuclear fuel production and processing. Understanding the fate and transport of contamination is hindered by the presence of multiple potential contamination sources within relatively small areas, and the extended 50-year duration of activity. Natural sources of uranium have a uniform ${ }^{238} \mathrm{U} /{ }^{235} \mathrm{U}$ ratio (with the rare exception of the Oklo natural fission reactor (1)), but can have variable ${ }^{234} \mathrm{U} /{ }^{238} \mathrm{U}$ depending on natural processes that can disturb the secular equilibrium of the ${ }^{238} U$ decay chain. In contrast, anthropogenic $U$ can have altered ${ }^{238} U /{ }^{235} U$ due either to ${ }^{235} \mathrm{U}$ enrichment for nuclear applications or to changes resulting from the burn up of natural or enriched uranium in nuclear reactors. In addition, the consumption of uranium fuel rods in reactors produces ${ }^{236} \mathrm{U}$ (half-life $=23$ million years) through neutron capture by ${ }^{235} \mathrm{U} .{ }^{236} \mathrm{U}$ does not occur naturally to any significant degree. These contrasts in the isotopic compositions of natural and anthropogenic uranium, as well as the wide variation in the isotopic composition 
of different anthropogenic uranium sources, promotes the measurement of uranium isotopic composition as a tracer of uranium contamination in the environment (e.g., refs 2-4).

Multiple collector ICP magnetic sector mass spectrometry (MC-ICPMS) provides high precision isotopic analyses of a wide range of elements $(5,6$, also see overview 7). MC-ICPMS has been used for high precision ${ }^{234} \mathrm{U} /{ }^{238} \mathrm{U}$ measurements (8) and for $\mathrm{U}$-series disequilibrium dating (e.g. 9, 10). For environmental applications, MC-ICPMS has the advantage of high sensitivity, high precision in isotopic measurement, and, unlike alpha spectroscopy, the ability to distinguish between ${ }^{236} U$ and ${ }^{235} U$. Here we report high precision measurements of ${ }^{234} U /{ }^{238} U$, ${ }^{238} \mathrm{U} /{ }^{235} \mathrm{U}$ and ${ }^{236} \mathrm{U} /{ }^{238} \mathrm{U}$ of uranium from vadose zone samples obtained from two contaminated cores in the B-BX-BY Waste Management Area (WMA), as well as U from groundwater samples. The isotopic analyses are used to investigate the link between vadose zone and groundwater contamination, to identify contamination sources, and to provide estimates of the relative proportions of contaminant uranium in the analyzed samples. In addition, the uranium isotopic compositions measured in the vadose zone and groundwater samples can be related to estimates of the uranium isotopic compositions of different waste fluids to constrain the history of contamination events in the B-BX-BY tank farm.

Geologic and Hydrogeologic Settings. The Hanford Site sits on the Columbia Plateau within the Pasco Basin, formed by broad folding and faulting of the Columbia River Basalts and overlying sediments. The geology and hydrogeology of the Hanford Site have been summarized by Hartman (11). The stratigraphy underlying the site consists of: Miocene age Columbia River basalts, Pliocene fluvial and lacustrine sedimentary deposits of the Ringold Formation, a zone of pedogenic carbonate development at the top of the Ringold Fm. called the Cold Creek Unit, and Pleistocene episodic catastrophic flood deposits of the Hanford formation (see Fig. 2). In the BBX-BY WMA, the water table is currently at $\sim 78 \mathrm{~m}$ depth, in the coarse gravels of the Cold Creek Unit (Fig. 2), and the unconfined aquifer is only about 1.8 to $3.7 \mathrm{~m}$ thick. The vadose zone is within sands and gravels of the Hanford Fm, and contains thin (10's cm to mm scale) intervals of fine sand to silt.

In the B-BX-BY WMA, the hydraulic gradient is currently minimal making the local groundwater flow direction difficult to determine (12). However, past site activities artificially increased local recharge and disturbed the water table over much of the site. Since the end of 
production in the late 1980's, the water table has dropped by as much as $8 \mathrm{~m}$ locally, while in the B-BX-BY WMA it has dropped by $2 \mathrm{~m}$. From the geometry of contaminant plumes, it appears that groundwater flow has been to the northwest, consistent with the flow regime during site operations. Recent studies of flow directions in the northern 200-East Area have provided widely varying results (12).

Sampling Context. The analyzed vadose sediment samples come from two cores taken by PNNL (Pacific Northwest National Laboratory) to delineate contamination plumes within the vadose zone in the B-BX-BY WMA (Fig. 1). Core E33-45 is near tank BX-102 that in 1951 was involved in a large overflow event that released over $300 \mathrm{~kL}$ of high level waste to the vadose zone (13). Core E33-46 is from near tank B-110 that is estimated to have leaked approximately $53 \mathrm{~kL}$ via a transfer line around 1965 to 1969 (13).

Analyzed water samples come from groundwater monitoring wells in the vicinity of the BBX-BY WMA (Fig. 1). At the times of well sampling for this study (mid-2001), the groundwater plume (>20 ppb U) was known to be approximately $250 \mathrm{~m}$ wide, at least $900 \mathrm{~m}$ long with $\mathrm{U}$ concentrations up to $525 \mathrm{ppb}(14)$. Observed concentrations in the most contaminated wells (E33-9 and E33-44) appeared to peak in 2001 (15). The source of this plume is uncertain.

\section{Analytical Methods}

Depths of the analyzed core samples are provided in Tables 1A and 1B and shown in Fig. 2. Analyses were conducted on pore water extracted from core sediment samples using 1:1 (by weight) de-ionized water (DI) rinses. Concentrations of total $U$ for the rinses were determined by ICP-MS at PNNL $(16,17)$. Aliquots were analyzed of groundwater samples collected from wells (see Dresel et al. (14) for sampling protocols) during mid-2001. U isotopic analyses of groundwater samples presented here replicate at higher precision most of the analyses reported by Dresel et al. (14) for the B-BX-BY area. Well locations are shown in Fig. 1, and sampling dates are given in Table 2. For the isotopic analyses the uranium was chemically separated from the allotted sample aliquots using TRU-SPEC (Eichrom Ind. Inc.) in small volume Teflon columns scaled down from the procedure of Luo et al. (8). The separation scheme provided column $\mathrm{U}$ yields of $\geq 95 \%$. 
The uranium isotopic compositions $\left({ }^{234} \mathrm{U} /{ }^{238} \mathrm{U},{ }^{238} \mathrm{U} /{ }^{235} \mathrm{U}\right.$ and $\left.{ }^{236} \mathrm{U} /{ }^{238} \mathrm{U}\right)$ were measured on a Micromass IsoProbe (MC-ICPMS) at LBNL (Lawrence Berkeley National Laboratory). Uranium isotopes 235 and 238 were measured simultaneously on separate Faraday cups, while 234 and 236 were measured on a Daly ion counting system situated behind a wide-angle retardation potential lens. Two separate static simultaneous measurement routines were used, one for ${ }^{238} \mathrm{U} /{ }^{235} \mathrm{U}$ and ${ }^{234} \mathrm{U} /{ }^{238} \mathrm{U}$ and a second for ${ }^{236} \mathrm{U} /{ }^{238} \mathrm{U}$. Corrections for mass fractionation, Daly-Faraday inter-calibration and for any peak-tail under mass 236 were calculated from bracketed analyses of an in-house secular equilibrium natural uranium standard (U ore from the Schwartzwalder Mine, CO provided by W. Sharp, Berkeley Geochronology Center). Isotopic compositions were normalized to the natural ${ }^{238} \mathrm{U}^{235} \mathrm{U}$ ratio $(=137.88$ by convention (18)) of the standard solution using an exponential mass fractionation law. Sample solutions were introduced to the MC-ICPMS via a desolvation system (Aridus manufactured by CETAC Inc.) equipped with a low uptake micro-concentric nebulizer. The uranium concentrations and isotopic compositions are compiled for core E33-45 in Table 1A, for core E33-46 in Table 1B and for the groundwater samples in Table 2. Statistical analyses and linear regressions were conducted using Isoplot (19). Typical precision for ${ }^{238} \mathrm{U} /{ }^{235} \mathrm{U}$ is $\pm 0.05 \% 2 \square$ or better, for ${ }^{234} \mathrm{U} /{ }^{238} \mathrm{U}$ and ${ }^{236} \mathrm{U} /{ }^{238} \mathrm{U}$ it is $\pm 0.15 \% 2 \square .{ }^{236} \mathrm{U} /{ }^{238} \mathrm{U}$ can be measured down to the $10^{-7}$ range where precision degrades by about a factor of ten.

\section{Results}

Borehole 299-E33-45. Twelve samples were measured from core E33-45 near tank BX-102 (Table 1a). The uranium concentrations of the pore water rinses outline a distinct plume between 22 and $62 \mathrm{~m}$ depth in the core, with a peak in $\mathrm{U}$ concentration at about 36-40 m depth (Fig. 2a). Nine of the samples analyzed come from this plume region, including the highest concentration sample. The $\mathrm{U}$ isotopic compositions of these nine samples are essentially identical in ${ }^{234} \mathrm{U} /{ }^{238} \mathrm{U}$, ${ }^{238} \mathrm{U} /{ }^{235} \mathrm{U}$ and ${ }^{236} \mathrm{U} /{ }^{238} \mathrm{U}$ across the uranium contamination plume. The weighted average ratios are: ${ }^{234} \mathrm{U} /{ }^{238} \mathrm{U}=5.3979 \times 10^{-5}( \pm 0.097 \%, 95 \%$ confidence limits $),{ }^{238} \mathrm{U} /{ }^{235} \mathrm{U}=147.889( \pm 0.014 \%$, $95 \%$ confid.) and ${ }^{236} \mathrm{U} /{ }^{238} \mathrm{U}=7.870 \times 10^{-5}( \pm 0.16 \%, 95 \%$ confid. $)$. The extremely high $\mathrm{U}$ concentrations of the plume samples (from $4.8 \mathrm{ppm}$ to $660 \mathrm{ppm}$ calculated for pore water in the plume compared to background values of 15-150 ppb), and the consistency of their measured U 
isotopic compositions, indicate that this is the isotopic signature of the $\mathrm{U}$ contaminant. In contrast, a sample (S01014-116A) from within a perched water body at $70.5 \mathrm{~m}$ depth has a distinct isotopic composition $\left({ }^{234} \mathrm{U} /{ }^{238} \mathrm{U}=5.748 \times 10^{-5}( \pm 0.19 \% 2 \square),{ }^{238} \mathrm{U} /{ }^{235} \mathrm{U}=138.950( \pm 0.029 \%\right.$ $2 \square)$ and ${ }^{236} \mathrm{U}^{238} \mathrm{U}=8.17 \times 10^{-6}( \pm 0.2 \% 2 \square)$ ). Two samples (S01014-1A and S01014-6A) from near the top of the E33-45 core from depths of $3.2 \mathrm{~m}$ and $6.3 \mathrm{~m}$ have near normal isotopic compositions $\left({ }^{238} \mathrm{U} /{ }^{235} \mathrm{U}=138.142\right.$ and 138.116 respectively), but with measurable ${ }^{236} \mathrm{U} /{ }^{238} \mathrm{U}$ $\left(6.6 \times 10^{-7}\right.$ and $5.5 \times 10^{-7}$ respectively).

The data for E33-45 are presented on a plot of ${ }^{236} \mathrm{U} /{ }^{238} \mathrm{U}$ vs. ${ }^{238} \mathrm{U} /{ }^{235} \mathrm{U}$ in Fig. 3a. On such a plot, natural $U$ should plot on the $x$-axis $\left({ }^{236} U /{ }^{238} U=0\right)$ at a value of ${ }^{238} U /{ }^{235} U=137.88 \pm 0.04$ (18). The U isotopic compositions representing the plume in E33-45 form a tight cluster, while the perched water zone sample and the two shallow samples fall closer to the ${ }^{238} \mathrm{U} /{ }^{235} \mathrm{U}$ axis. A best-fit line through the plume data (nine points) and the data for S01014-116A from the perched water zone gives an intercept of $137.92 \pm 0.04( \pm 2 \square, M S W D=0.98)$, within error of the ${ }^{238} U /{ }^{235} U$ of natural uranium, which is known absolutely to about $0.1 \%(20,21)$. This suggests that the sample S01014-116A consists of a mixture of natural uranium and contaminant uranium. Assuming the weighted average ${ }^{238} U /{ }^{235} U(=147.889 \pm 0.021)$ of the plume samples as the end member contaminant, then $10.7 \pm 0.4 \%$ of the uranium in that sample is contaminant $\mathrm{U}$. A similar calculation based on ${ }^{236} \mathrm{U} /{ }^{238} \mathrm{U}$ gives an indistinguishable but better constrained result of $10.44 \pm 0.07 \%$. Likewise, plotting ${ }^{234} \mathrm{U} /{ }^{238} \mathrm{U}$ against ${ }^{236} \mathrm{U} /{ }^{238} \mathrm{U}$ (see Fig. 3b) can give an estimate for the pre-contamination ${ }^{234} U /{ }^{238} U$ of sample $116 A$. At ${ }^{236} U / /{ }^{238} U=0$, the ${ }^{234} U /{ }^{238} U$ is $5.789 \pm 0.022$ $\mathrm{x} 10^{-5}( \pm 95 \%, \mathrm{MSWD}=2.8)$ which indicates an excess of ${ }^{234} \mathrm{U}$ relative to ${ }^{238} \mathrm{U}\left({ }^{234} \mathrm{U} /{ }^{238} \mathrm{U}\right.$ activity ratio $=1.056 \pm 4$ ) as is typical of natural groundwater samples (22). Similar calculations based on ${ }^{236} \mathrm{U} /{ }^{238} \mathrm{U}$ can be made for samples S01014-1A and S01014-6A, indicating < 1\% contaminant $\mathrm{U}$ in those shallow samples $(0.90 \pm 0.02 \%$ and $0.76 \pm 0.03 \%$ respectively $)$. The ${ }^{234} \mathrm{U} /{ }^{238} \mathrm{U}$ of these two samples corrected for the contaminant component are, for $1 \mathrm{~A}=5.989 \pm 0.007 \times 10^{-5}$, and for $6 \mathrm{~A}=$ $6.024 \pm 0.011 \times 10^{-5}$. Therefore, both these samples exhibit similar excesses of ${ }^{234} U\left({ }^{234} U /{ }^{238} U\right.$ activity ratios of $1.092 \pm 0.001$ and $1.099 \pm 0.002$ ).

Borehole 299-E33-46. Eleven samples were analyzed from E33-46 near tank B-110 (Table 1b). The calculated pore water $U$ concentrations in this core are much lower than in E33-46, with $\sim 9.7$ ppm being the highest concentration found. From the concentration data (Fig. 2b), the U 
contamination plume covers a depth range from approximately $15 \mathrm{~m}$ to $38 \mathrm{~m}$, with a peak concentration at $\sim 21 \mathrm{~m}$ depth. Eight samples are from this zone, two from greater depth (samples S01052-82A from $164.5 \mathrm{ft}$ and S01052-90A from $180 \mathrm{ft}$ ) and one (S01052-06A) from within the artificial backfill at a depth of $6.4 \mathrm{~m}$. Unfortunately, the sample with the highest $\mathrm{U}$ concentration, at $21 \mathrm{~m}$ depth, was not available for $U$ isotopic analysis, but the next highest concentration samples were analyzed.

The eight samples from the E33-46 plume exhibit a significant range in isotopic composition compared to the E33-45 plume (Table 1b). The two highest concentration samples analyzed (S01052-38A and -36A), though, have nearly identical isotopic compositions and are likely to represent the composition of the contaminant uranium. The average isotopic compositions of those two samples are: ${ }^{234} \mathrm{U} /{ }^{238} \mathrm{U}=5.434 \times 10^{-5}( \pm 0.057 \%, 95 \%$ confidence $),{ }^{238} \mathrm{U} /{ }^{235} \mathrm{U}=144.492$ $( \pm 0.056 \%, 95 \%)$, and ${ }^{236} \mathrm{U} /{ }^{238} \mathrm{U}=5.359 \times 10^{-5}( \pm 0.12 \%, 2 \square$ internal $)$. The data for the E33-46 samples are also plotted on Fig. 3a. The best-fit line to the plume data has an intercept of $137.92 \pm 0.18$ (95\% confid. MSWD=17), indistinguishable from the value for natural uranium. In a plot of ${ }^{236} \mathrm{U} /{ }^{238} \mathrm{U}$ vs. ${ }^{234} \mathrm{U} /{ }^{238} \mathrm{U}$ (Fig. 3b) the data for the E33-46 vadose zone plume forms a linear array with an intercept at ${ }^{234} U{ }^{238} U=6.091 \pm 0.028 \times 10^{-5}( \pm 2 \square \mathrm{MSWD}=11)$. This value falls roughly at the mean of the measured ${ }^{234} \mathrm{U} /{ }^{238} \mathrm{U}$ of the three remaining samples (S01052-06A, S01052-82A and S01052-90A) that have very low ${ }^{236} U /{ }^{238} U$ and ${ }^{238} U /{ }^{235} U$ very close (S01052-06A and S01052-82A) or indistinguishable (S01052-90A) from the natural ratio. The samples from the plume zone vary from essentially $100 \%$ contaminant to $0.8 \%$ contaminant $\mathrm{U}$ (Table 1b), based on the of the measured ${ }^{236} \mathrm{U} /{ }^{238} \mathrm{U}$ and the assumption that samples S01052-38A and S01052-36A represent the composition (ave. ${ }^{236} \mathrm{U} /{ }^{238} \mathrm{U}=5.39 \times 10^{-5}$ ) of the contaminant uranium (see above, Table 1). The percentage of contaminant uranium can be used to estimate the concentration of natural uranium in the samples. These corrected values are given in Table 1b. In general, the corrected uranium concentrations appear consistent with the stratigraphy.

B-BX-BY Area Groundwater Samples. Samples from nine wells were measured, covering the extent of the groundwater plume as known in 2001 and including wells just outside the plume, as defined by the $20 \mathrm{ppb}$ concentration contour. The groundwater $\mathrm{U}$ concentrations (Fig. 1, Table 2) range from $3.5 \mathrm{ppb}$ (well E33-7) to $420 \mathrm{ppb}$ (well E33-44). The analyzed samples cover a range in isotopic composition (Fig. 3a). The ${ }^{236} \mathrm{U} /{ }^{238} \mathrm{U}$ and ${ }^{238} \mathrm{U} /{ }^{235} \mathrm{U}$ ratios of the groundwater 
samples fall along a line between the E33-45 vadose zone plume data and the natural isotopic composition of uranium. One sample, E33-32, from a well furthest from the plume, appears to fall off this line. Excluding this sample, the best-fit line to the groundwater data has an intercept of $137.76 \pm 0.10$ (95\% confid. MSWD=3.7), indistinguishable from natural uranium. This indicates that the groundwater data can be explained by mixing between background natural $\mathrm{U}$ and a single end-member contaminant. In the case of the sample from well E33-32, a different or additional component may be necessary. The ${ }^{236} \mathrm{U} /{ }^{238} \mathrm{U}$ and ${ }^{234} \mathrm{U} /{ }^{238} \mathrm{U}$ ratios for the groundwater samples form an array between the E33-45 vadose zone plume composition and a high ${ }^{234} \mathrm{U} /{ }^{238} \mathrm{U}$ ratio consistent with natural groundwater U (Fig. 3b).

\section{Discussion}

\section{The Source of the B-BX-BY Area Groundwater Uranium Plume}

The uranium isotopic data provide several lines of evidence for the source of the B-BX-BY groundwater $\mathrm{U}$ plume. The highest concentration groundwater sample closely approaches the isotopic composition of the E33-45 vadose zone plume, with the other samples falling along the line connecting the samples to natural U composition in decreasing order of concentration (Fig. 3a). This systematic relationship is most likely a result of mixing between natural background $U$ and a contaminant composition represented by the E33-45 vadose zone plume, rather than each groundwater sample representing contamination from different sources. This conclusion is further supported by the relationships seen in Fig. 3b, in which ${ }^{234} U /{ }^{238} U$ provides additional signatures for natural $\mathrm{U}$ and contaminant $\mathrm{U}$, due to alpha recoil effects that impart to groundwater and pore water a higher ${ }^{234} U /{ }^{238} U$ than the secular equilibrium ratio. In Fig. $3 b$ the E33-45 and E33-46 vadose zone U plumes are well separated. The groundwater data form an array between the E33-45 plume and a groundwater component with elevated ${ }^{234} \mathrm{U} /{ }^{238} \mathrm{U}$ and zero ${ }^{236} \mathrm{U}$, eliminating the E33-46 vadose zone plume as a contributor to the contamination. The natural groundwater component is approximated by the sample from well E33-7 which has low ${ }^{236} \mathrm{U} /{ }^{238} \mathrm{U}\left(=1.66 \times 10^{-6}\right)$ and nearly normal ${ }^{238} \mathrm{U} /{ }^{235} \mathrm{U}(=137.99 \pm 0.04)$, but a high ${ }^{234} \mathrm{U} /{ }^{238} \mathrm{U}$ $\left(=6.695 \times 10^{-5}\right)$, indicating that uncontaminated groundwater has ${ }^{234} \mathrm{U} /{ }^{238} \mathrm{U}$ further from secular equilibrium than uncontaminated pore waters in the E33-45 and E33-46 cores. The E33-32 well is the furthest sampled well from the plume, and may involve a different contaminant composition and therefore a different source. That it plots to the left of the mixing line in Fig. 3a 
suggests a high ${ }^{236} \mathrm{U} /{ }^{238} \mathrm{U}$ compared to ${ }^{238} \mathrm{U} /{ }^{235} \mathrm{U}$, and so a minor component of enriched ${ }^{235} \mathrm{U}$ fuel. Future sampling of this well, along with sampling of additional nearby wells may resolve this issue.

Assuming the average ${ }^{236} \mathrm{U} /{ }^{238} \mathrm{U}$ found for the E33-45 vadose zone plume, the percentage of contaminant $\mathrm{U}$ and the pre-contamination concentration of $\mathrm{U}$ in each groundwater sample can be calculated (Table 3). This gives a range of $\sim 3 \mathrm{ppb}$ to $8 \mathrm{ppb}$ for the pre-contamination concentration of $U$ and a range of the percentage of contamination of $2 \%$ (E33-7) to a high of 98\% (E33-44). The range in pre-contamination concentration is very similar to that seen in background wells outside the B-BX-BY area (15). The average ${ }^{236} U /{ }^{238} U$ and ${ }^{234} U /{ }^{238} U$ of the E33-45 vadose zone plume can also be used to calculate a pre-contamination ${ }^{234} \mathrm{U} /{ }^{238} \mathrm{U}$ for the groundwater samples (Table 3 ). There is a rough negative correlation between the calculated pre-contamination groundwater ${ }^{234} \mathrm{U} /{ }^{238} \mathrm{U}$ and the calculated pre-contamination groundwater $\mathrm{U}$ concentration (Fig. 4). This is consistent with the behavior of groundwater $U$, where natural ${ }^{234} U$ from alpha-recoil effects is diluted by secular equilibrium $U$ derived from weathering (22). The calculated pre-contamination ${ }^{234} \mathrm{U} /{ }^{238} \mathrm{U}$ provides a potential label for groundwater $\mathrm{U}$ for the backtracking of ground-water flow paths (23), once a wider survey in the Hanford Site of groundwater ${ }^{234} \mathrm{U} /{ }^{238} \mathrm{U}$ is conducted.

History of Uranium Contamination. The isotopic composition of the B-BX-BY groundwater U plume is consistent with the model estimates of production from the Al clad- $0.71 \%{ }^{235} \mathrm{U}$ (natural uranium) fuel type, rather than fuels with enriched ${ }^{235} \mathrm{U}$ contents (14). In addition, Dresel et al. (14) provide model histories of the abundances of ${ }^{234} \mathrm{U},{ }^{235} \mathrm{U}$ and ${ }^{236} \mathrm{U}$ of the fuel rods that were processed by the Hanford plants (24). The average abundances of ${ }^{235} \mathrm{U}, 6.72 \times 10^{-3}$, and ${ }^{236} \mathrm{U}$ abundance, $7.82 \times 10^{-5}$, for the E33-45 vadose zone plume are consistent with the composition of natural $\mathrm{U}$ fuel rods processed in approximately 1951 (Fig. 5). This supports the inference from gamma logs (13) that the $1951 \mathrm{BX}-102$ overflow event is the source of the vadose zone contamination seen in core E33-45. The abundance of ${ }^{234} U$ only increased slightly with burn up of the $\mathrm{Al} 0.71 \%{ }^{235} \mathrm{U}$ fuel, but the average ${ }^{234} \mathrm{U}$ abundance, $5.36 \times 10^{-5}$, for the E33-45 plume is 
consistent with the A1-0.71\% ${ }^{235} \mathrm{U}$ fuel and distinct from other enriched fuel types processed later.

Given the large volume of material spilled from BX-102, it might be supposed that the E3346 plume is a diluted mixture of BX-102 uranium and background uranium scavenged during lateral spreading of the contaminant fluid. But, the isotopic evidence does not support this possibility. In Fig. 3b, the data for the E33-46 plume forms a linear array that represents mixing between contaminant uranium and natural pore water $\mathrm{U}$, as was also concluded from Fig. $3 \mathrm{a}$. However, the E33-45 vadose zone plume samples plot off the line defined by the E33-46 samples. This indicates there probably were separate sources for the E33-45 and E33-46 plumes. This distinction can also be expressed in terms of the ${ }^{236} \mathrm{U} /{ }^{234} \mathrm{U}$ of the two vadose zone plumes. The ${ }^{236} \mathrm{U} /{ }^{234} \mathrm{U}$ for the E33-45 plume is $1.489 \pm 0.003$, which is distinct from the ${ }^{236} \mathrm{U} /{ }^{234} \mathrm{U}$ $(0.986 \pm 0.001)$ of the E33-46 plume (represented by samples S01052-36A and S01052-38A).

The implication of the isotopic analyses is that most, if not all, of the uranium in the groundwater samples from the B-BX-BY area is consistent with contamination by $\mathrm{U}$ from the 1951 BX-102 overflow event. Recent modeling of the supernatant chemical compositions for the B-BX-BY tanks (25) that indicates that BX-102 had the highest supernatant uranium concentration (by several orders of magnitude) supports this conclusion. This, together with the large volume of that leak (347,000 liters of solution), suggests it as an important source of uranium contamination in the area. It should be noted, however, that there are several liquid waste disposal facilities in close proximity to the B-BX-BY tanks that were in operation during the late 1940's and early 1950's (26). With no vadose zone samples from those facilities, our study cannot rule them out as sources of groundwater contamination.

The isotopic composition of the E33-46 vadose zone U plume does not match the isotopic composition estimated by Jones et al. (13) for the 1965/1969 leak from the B-110 tank (Fig. 3). The estimate by Jones et al. (13) presumes a mixture of processed natural U and enriched fuel rods, as might be expected from the late 1960's. Even if this estimate is in error, the E33-46 plume ${ }^{236} \mathrm{U}$ abundance $\left(5.322 \times 10^{-5}\right)$ and ${ }^{235} \mathrm{U}$ abundance $\left(6.873 \times 10^{-3}\right)$ would appear to be inconsistent with the composition of most natural U fuel processed in the late 1960's (see estimates by Dresel et al. (14)). Rather, the E33-46 composition is more likely to be natural U 
fuel from early in the history of processing, possibly before 1950 (Fig. 5). Therefore, it appears that the vadose plume in the E33-46 core is not related to the 1965/1969 leak from the B-110 tank, but related to an earlier unrecorded event or leak. Tank B-110 was placed in service in May 1945 and filled by December 1945, making it one of the first used in the area (27). By virtue of the fact that the ${ }^{236} \mathrm{U} /{ }^{238} \mathrm{U}$ (or ${ }^{236} \mathrm{U}$ abundance) for E33-46 is lower than that of E33-45, the contaminant appears to be waste generated earlier than the BX-102 overflow event. On the basis of the isotopic differences between the leak and the groundwater contamination, the B-110 leak was probably not a significant source of uranium contamination in groundwater.

Having made a case for the E33-45 vadose U plume (and hence the 1951 BX-102 overflow event) being the source of the B-BX-BY ground water plume, there are implications for the path and history of $U$ transport. The initial locus of groundwater contamination was displaced from the vadose zone source by as much as $150 \mathrm{~m}$ to the northeast. Comparing this distance to the vertical distance to the water table of the contamination in E33-45 implies more than an 8:1 ratio of horizontal to vertical migration of the contaminant $U$ within the vadose zone before contamination of the groundwater. This may have resulted from the strong anisotropy in the vertical permeability due to the presence of fine sedimentary layers in the stratigraphy (28). The time of groundwater contamination is also significantly displaced from the time of the 1951 overflow event that contaminated the vadose zone sediments. From an examination of monitoring well records, the first sign of U contamination appeared in well E33-18 in early 1993 and peaked in mid-1997. Unfortunately records for other wells are incomplete, especially for E33-9 and E33-44, which showed the highest U concentrations in 2001. For well E33-34, about 775 m down gradient from E33-18 along the axis of the plume (Fig. 1), the first appearance of elevated U concentrations was about mid-1995 to early-1996. Thus about 2.5 to 3 years was necessary for the contaminant uranium to migrate from E33-18, presumed to be close to the locus of initial contamination, to E33-34 implying a rate of 0.7 to $0.8 \mathrm{~m} /$ day. This is somewhat less than a groundwater flow rate of $1 \mathrm{~m} /$ day calculated from measured data for 2000 (15), but is consistent considering that some retardation of $\mathrm{U}$ migration relative to groundwater movement is likely (e.g. 2).

The current ground-water contamination appears to have resulted from an episodic event given the relatively limited size of the plume and declining concentrations near the source area. 
Since over 50 years separates the vadose zone spill and the groundwater contamination that was detected in the early 1990s, we can not say whether there were prior undetected events. It is also not known whether contamination reached the water table in 1951, but if so, it appears that it had dissipated by the early 1990's before the appearance of the current plume. By about 2001, U concentrations in monitoring wells in the area had begun to diminish (15) as the plume migrates and attenuates. But the connection between the significant $U$ contamination seen in the vadose zone near tank BX-102 and groundwater contamination indicates a continuing potential for future contamination events from this source.

\section{Acknowledgments}

This work was supported by the Assistant Secretary of the Office of Environmental Management, Office of Science and Technology, Environmental Management Science Program, of the U.S. Department of Energy under Contract No. DE-AC03-76SF00098 to LBNL and Contract No. DE-AC06-76RL01830 to PNNL. Laboratory support, and general support for the development of isotopic methods in hydrology, is provided by the Director, Office of Energy Research, Basic Energy Sciences, Chemical Sciences, Geosciences and Biosciences Division of the U.S. Department of Energy under Contract No. De-AC03-76SF00098 to LBNL. The assistance of Rachel Lindvall in the $\mathrm{U}$ isotopic analyses is gratefully acknowledged. We would also like to thank the Hanford Groundwater Monitoring Project at PNNL for support of sampling co-ordination, as well as Jeff Serne for providing aliquots of vadose zone pore water samples. 


\section{References}

(1) Lancelot, J.R.; Vitrac, A.; Allegre, C.J. Earth Planetary Sci. Lttrs. 1975, 25, 189-196.

(2) Beasley, T.M.; Dixon, P.R.; Mann, L.J. Environ. Sci. Technol. 1998, 32, 3875-3881.

(3) Ketterer, M.E.; Wetzel, W.C.; Layman, R.R.; Matisoff, G.; Bonniwell, E.C. Environ. Sci. Technol., 2000, 34, 966-972.

(4) Yoshida, S.; Muramatsu, Y.; Tagami, K. Environ. Sci. Technol. 2001, 35, 4174-4179.

(5) Walder, A.J.; Freedman, P.A. J. Anal. Atomic Spect. 1992, 7, 571-575.

(6) Walder, A.J.; Koller, D.; Reed, N.M.; Hutton, R.C.; Freedman, P.A. J. Anal. Atomic Spec. 1993, 8, 19-23.

(7) Halliday, A.N.; Lee, D.-C.; Christensen, J.N.; Rehkämper, M.; Yi, W.; Luo, X.; Hall, C.M.; Ballentine, C.J.; Pettke, T.; Stirling, C. Geochim. Cosmochim. Acta 1998, 62, 919-940.

(8) Luo, X.Z.; Rehkämper, M.; Lee, D.-C.; Halliday, A.N. Int. Jour. Mass Spectrometry Ion Processes 1997, 171, 105-117.

(9) Stirling, C.H.; Lee, D.-C.; Christensen, J.N.; Halliday, A.N. Geochim. Cosmochim. Acta. 2000, 64, 3737-3750.

(10) Stirling, C.H.; Esat, T.M.; Lambeck , K.; McCulloch, M.T.; Blake, S.G.; Lee, D.-C.; Halliday, A.N. Science 2001, 291, 290-293.

(11) Hartman, M.J., ed. Hanford Site Groundwater Monitoring: Setting, Sources and Methods. PNNL-13080. Pacific Northwest Nat. Lab., Richland, WA. 2000

(12) Hartman et al. eds. Hanford Site Groundwater Monitoring for Fiscal Year 2001 PNNL 14187, Pacific Northwest National Laboratory, Richland, WA. 2003

(13) Jones, T. E.; Simpson, B. C.; Wood, M. I.; and Corbin, R. A. Preliminary Inventory Estimates for Single-Shell Tank Leaks in B, BX, and BY Tank Farms. RPP-7389, CH2M HILL Hanford Group, Inc., Richland, WA. 2001

(14) Dresel, P. E.; Evans, J. C.; Farmer III, O. T. Investigation of isotopic signatures for sources of groundwater contamination at the Hanford Site. PNNL-13763, Pacific Northwest Natl. Lab., Richland, WA. 2002

(15) Hartman et al. eds. Hanford Site Groundwater Monitoring for Fiscal Year 2001. PNNL 13788, Pacific Northwest Nat. Lab., Richland, WA. 2002

(16) Serne, R.J. and fifteen others Characterization of vadose zone sediment: Borehole 299-E3345 near BX-102 in the B-BX-BY Waste Management Area. PNNL-14083, Pacific Northwest Nat. Lab., Richland, Washington. 2003

(17) Serne, R.J. and sixteen others Characterization of vadose zone sediment: Borehole 299E33-46 near B-110 in the B-BX-BY Waste Management Area. PNNL-14119, Pacific Northwest Nat. Lab., Richland, WA, 2003.

(18) Steiger, R.H.; Jäger, E. Earth Planetary Sci. Lttrs., 1977, 36, 359-362.

(19) Ludwig, K. Isoplot/Ex Version 2.49. Berkeley Geochronology Center. 2002. 
(20) Cheng, H.; Edwards, R.L.; Hoff, J.; Gallup, C.D.; Richards, D.A.; Asmerom, Y. Chem. Geol. 2000, 169, 17-33.

(21) Cowan, G.A.; Adler, H.H. Geochim. Cosmochim. Acta. 1976, 40, 1487-1490.

(22) Osmond, J.K. and Cowart, J.B. in Uranium Series Disequilibrium: Applications to Earth, Marine and Environmental Sciences (eds. M. Ivanovich and RS Harmon) pp.290-333. Clarendon Press, Oxford, U.K., 1992.

(23) Roback, R.C.; Johnson, T.M.; McLing, T.L.; Murrell, M.T.; Luo, S.; and Ku, T.-L. Geol. Soc. Amer. Bull. 2001, 113, 1133-1141.

(24) Watrous, R.A.; Wootan, D.W. Activity of Fuel Batches Processed Through Hanford Separations Plants, 1944 Through 1989. HNF-SD-WM-TI-794, Rev. 0, Lockheed Martin Hanford Corporation, Richland, WA, 1997.

(25) Lichtner, P.C. (2003) Simulated B-BX-BY Tank Farms Supernate Compositions. In RPP10098. Pacific Northwest Nat. Lab., Richland, WA, 2003.

(26) Narbutovskih, S.M. Results of Phase I Groundwater Quality Assessment for the Single-Shell Tank Waste Management Areas B-BX-BY at the Hanford Site. PNNL-11826. Pacific Northwest Nat. Lab., Richland, WA, 1998.

(27) Anderson, J.D. A history of the 200 Area Tank Farms. WHC-MR-0132 Westinghouse Hanford Company, Richland, WA, 1990.

(28) Pruess, K.; Yabusaki, S. Modeling Studies of Fluid Flow and Solute Transport at Tank BX102 in the Hanford Vadose Zone. In RPP-10098. Pacific Northwest Nat. Lab., Richland, WA, 2003. 


\section{Figure Captions}

Fig. 1. Map of the B-BX-BY Waste Management Area in the 200 East area, Hanford Washington. Shown are locations of sampled monitoring wells, and two vadose zone sediment cores, E33-45 near tank BX-102 and E33-46 near tank B-110. Well E33-34 is off the map, approximately $235 \mathrm{~m}$ to the NW of well E33-26. Grey circles represent well samples analyzed by Quad ICP ID only (14).

Fig. 2. Profiles in 2a of core E33-45 and in $\mathbf{2 b}$ of core E33-46 showing U concentrations and analyzed samples (filled symbols). Also shown is stratigraphy for each of the cores $(16,17)$.

Fig. 3. Uranium isotopic data, in $3 \mathbf{a}^{236} \mathrm{U} /{ }^{238} \mathrm{U}$ vs. ${ }^{238} \mathrm{U} /{ }^{235} \mathrm{U}$, and in $\mathbf{3} \mathbf{b}^{236} \mathrm{U} /{ }^{238} \mathrm{U}$ vs. ${ }^{234} \mathrm{U} /{ }^{238} \mathrm{U}$. Black squares are data for water extractions from samples from the E33-45 (near tank BX-102) contaminated core, gray squares are data for water extractions of samples from the E33-46 (near tank B-110) contaminated core. Errors for data are approximately the size of the symbols or smaller. Black triangles are estimates by Jones et al. (13) of the uranium isotopic composition of tank leaks in the B-BX-BY area. Open circles are uranium isotopic data for groundwater samples, errors are approximately the size of the symbol or smaller. Grey stars are groundwater data from Dresel et al. (14) shown with $1 \%$ uncertainties.

Fig. 4. Concentration data and ${ }^{234} U{ }^{238} U$ for groundwater samples corrected for contamination based on the average ${ }^{236} U /{ }^{238} U$ for E33-45 (for concentration) and average ${ }^{236} U /{ }^{238} U$ and ${ }^{234} U /{ }^{238} U$ for E33-45 (for ${ }^{234} \mathrm{U} /{ }^{238} \mathrm{U}$ ). Errors are based on the isotopic measurements alone.

Fig. 5. Models of the abundances of ${ }^{236} U$ (top) and ${ }^{235} U$ (bottom) for irradiated natural $U$ fuel rods $(0.71 \% 235 \mathrm{U}-\mathrm{Al})$ for 1945 to 1954 from (14). Indicated by horizontal lines are the abundances of ${ }^{236} \mathrm{U}$ and ${ }^{235} \mathrm{U}$ in the contaminants identified in E33-45 and E33-46. B-plant operated from 1945 to mid-1952 and produced waste that was stored in the B-BX-BY WMA. 
Table 1A. Uranium isotopic data core E33-45 (near BX-102)

\begin{tabular}{|c|c|c|c|c|c|c|c|c|c|}
\hline Sample & $\begin{array}{c}\text { Ave. } \\
\text { depth, } \\
\text { meters }\end{array}$ & $\begin{array}{c}\mathrm{PW}[\mathrm{U}] \\
\mathrm{ppb}^{\mathrm{a}}\end{array}$ & $\begin{array}{c}234 \mathrm{U} / 238 \mathrm{U} \\
\mathrm{x} 10^{6}\end{array}$ & $\begin{array}{l} \pm 2 \square \\
x 10^{6}\end{array}$ & $238 \mathrm{U} / 235 \mathrm{U}$ & $\pm 2 \square$ & $\begin{array}{c}236 \mathrm{U} / 238 \mathrm{U} \\
\mathrm{x} 10^{6}\end{array}$ & $\begin{array}{c} \pm 2 \square \\
\times 10^{6}\end{array}$ & $\begin{array}{c}\% \\
\text { Conta. }^{\mathrm{b}}\end{array}$ \\
\hline S01014-01A & 3.2 & 44.1 & 59.84 & 0.06 & 138.142 & 0.067 & 0.712 & 0.012 & 0.90 \\
\hline S01014-06A & 6.4 & 14.6 & 60.19 & 0.10 & 138.116 & 0.059 & 0.602 & 0.019 & 0.76 \\
\hline S01014-33A & 22.4 & 29705.2 & 54.12 & 0.12 & 147.900 & 0.054 & 78.97 & 0.10 & 100 \\
\hline S01014-35A & 23.8 & 22406.3 & 54.12 & 0.14 & 147.888 & 0.061 & 78.51 & 0.09 & 100 \\
\hline S01014-40A & 27.0 & 9019.7 & 54.00 & 0.12 & 147.902 & 0.087 & 78.94 & 0.12 & 100 \\
\hline S01014-54A & 36.9 & 661396.2 & 53.98 & 0.04 & 147.861 & 0.046 & 78.82 & 0.15 & 100 \\
\hline S01014-72A & 46.2 & 92930.5 & 53.96 & 0.13 & 147.888 & 0.108 & 78.74 & 0.16 & 100 \\
\hline S01014-78A & 49.0 & 70364.4 & 54.12 & 0.16 & 147.906 & 0.068 & 78.72 & 0.11 & 100 \\
\hline S01014-82A & 51.4 & 5316.2 & 54.04 & 0.11 & 147.924 & 0.082 & 78.55 & 0.11 & 100 \\
\hline S01014-83A & 52.1 & 4804.5 & 53.87 & 0.07 & 147.99 & 0.15 & 78.81 & 0.13 & 100 \\
\hline S01014-93A & 58.1 & 47916.1 & 53.95 & 0.12 & 147.881 & 0.042 & 78.78 & 0.09 & 100 \\
\hline S01014-116A & 70.5 & 16.9 & 57.48 & 0.11 & 138.950 & 0.040 & 8.22 & 0.04 & 10.4 \\
\hline
\end{tabular}

Table 1B. Uranium isotopic data core E33-46 (near B-110)

\begin{tabular}{|c|c|r|r|r|r|r|r|r|r|}
\hline Sample & $\begin{array}{c}\text { Ave. } \\
\text { depth, } \\
\text { meters }\end{array}$ & $\begin{array}{c}\mathrm{PW}[\mathrm{U}] \\
\mathrm{ppb}^{\mathrm{a}}\end{array}$ & $\begin{array}{c}234 \mathrm{U} / 238 \mathrm{U} \\
\mathrm{x} 10^{6}\end{array}$ & $\begin{array}{l} \pm 2 \square \\
\times 10^{6}\end{array}$ & ${ }^{238 \mathrm{U} / 235 \mathrm{U}}$ & $\pm 2 \square$ & $\begin{array}{c}236 \mathrm{U} / 238 \mathrm{U} \\
\times 10^{6}\end{array}$ & $\begin{array}{c} \pm 2 \square \\
\mathrm{x} 10^{6}\end{array}$ & $\begin{array}{c}\% \\
\text { Conta. }^{\mathrm{b}}\end{array}$ \\
\hline S01052-06A & 6.4 & 24.1 & 62.45 & 0.12 & 138.051 & 0.071 & 0.789 & 0.011 & 1.47 \\
\hline S01052-21A & 16.2 & 69.4 & 56.33 & 0.11 & 142.496 & 0.052 & 35.20 & 0.08 & 65.68 \\
\hline S01052-26A & 18.5 & 560.2 & 54.44 & 0.06 & 144.368 & 0.036 & 52.15 & 0.07 & 97.31 \\
\hline S01052-36A & 24.4 & 2161.2 & 54.35 & 0.04 & 144.470 & 0.120 & 53.64 & 0.07 & 100 \\
\hline S01052-38A & 25.3 & 3425.0 & 54.34 & 0.04 & 144.510 & 0.110 & 53.46 & 0.12 & 100 \\
\hline S01052-42A & 27.6 & 160.2 & 56.24 & 0.12 & 142.333 & 0.074 & 35.79 & 0.07 & 66.78 \\
\hline S01052-47A & 30.1 & 580.3 & 55.96 & 0.05 & 142.974 & 0.044 & 39.46 & 0.04 & 73.63 \\
\hline S01052-53A & 34.0 & 150.1 & 60.27 & 0.12 & 138.724 & 0.020 & 6.78 & 0.05 & 12.66 \\
\hline S01052-57A & 36.6 & 141.4 & 60.81 & 0.06 & 137.881 & 0.051 & 0.437 & 0.004 & 0.82 \\
\hline S01052-82A & 50.2 & 42.8 & 60.39 & 0.12 & 137.966 & 0.070 & 0.209 & 0.005 & 0.39 \\
\hline S01052-90A & 54.8 & 27.2 & 59.87 & 0.08 & 137.901 & 0.041 & 0.303 & 0.005 & 0.57 \\
\hline
\end{tabular}

aPore water $\mathrm{U}$ concentrations from $(16,17)$

bPercent contaminant $U$ in pore water based on $236 \mathrm{U} / 238 \mathrm{U}$, see text 
Table 2. Uranium isotopic data for groundwater samples, B-BX-BY WMA

\begin{tabular}{|c|c|r|c|c|c|c|c|c|}
\hline Well & Date & $\begin{array}{c}\text { [U], } \\
\mathrm{ppb}^{\mathrm{a}}\end{array}$ & ${ }^{234 \mathrm{U} / 238 \mathrm{U} \times 10^{6}}$ & $\pm 2 \square \times 10^{6}$ & $238 \mathrm{U} / 235 \mathrm{U}$ & $\pm 2 \square$ & $236 \mathrm{U} / 238 \mathrm{U} \times 10^{6}$ & $\pm 2 \square \times 10^{6}$ \\
\hline E33-26 & $8 / 6 / 01$ & 92.84 & 54.613 & 0.045 & 147.461 & 0.026 & 74.290 & 0.080 \\
\hline E33-38 & $8 / 2 / 01$ & 119.05 & 54.517 & 0.057 & 147.542 & 0.034 & 75.419 & 0.080 \\
\hline E33-18 & $8 / 1 / 01$ & 122.70 & 54.316 & 0.069 & 147.738 & 0.064 & 75.993 & 0.099 \\
\hline E33-44 & $8 / 6 / 01$ & 411.70 & 54.092 & 0.073 & 147.818 & 0.041 & 77.155 & 0.192 \\
\hline E33-16 & $5 / 4 / 01$ & 14.46 & 59.204 & 0.082 & 143.147 & 0.080 & 41.50 & 0.055 \\
\hline E33-7 & $8 / 2 / 01$ & 3.46 & 66.955 & 0.059 & 137.992 & 0.040 & 1.66 & 0.01 \\
\hline E33-34 & $3 / 15 / 01$ & 22.40 & 56.441 & 0.062 & 146.135 & 0.036 & 64.619 & 0.070 \\
\hline E33-31 & $7 / 30 / 01$ & 60 & 55.153 & 0.055 & 147.092 & 0.050 & 71.930 & 0.109 \\
\hline E33-32 & $8 / 2 / 01$ & 4 & 66.419 & 0.070 & 139.584 & 0.036 & 18.108 & 0.030 \\
\hline
\end{tabular}

a. from (14) 
Table 3. Estimated pre-contamination U concentrations for groundwater samples

\begin{tabular}{|c|c|c|c|c|}
\hline Well & $\begin{array}{l}\text { Pre-contam. [U], ppb } \\
\pm 2 \mathrm{~s}^{\dagger}\end{array}$ & $\%$ Contam. & $\begin{array}{c}\text { Cor. }{ }^{234 \mathrm{U} / 238 \mathrm{U}} \\
\times 10^{6}\end{array}$ & $\pm 2 \square \times 10^{6}$ \\
\hline E33-26 & $5.2 \pm 0.17$ & 94 & 65.28 & 1.1 \\
\hline E33-38 & $5.0 \pm 0.22$ & 96 & 66.86 & 1.7 \\
\hline E33-18 & $4.2 \pm 0.24$ & 97 & 63.75 & 2.5 \\
\hline E33-44 & $8.1 \pm 1.2$ & 98 & 59.69 & 4.28 \\
\hline E33-16 & $6.8 \pm 0.02$ & 53 & 65.03 & 0.19 \\
\hline E33-7 & $3.39 \pm 0.001$ & 2 & 67.23 & 0.06 \\
\hline E33-34 & $4.0 \pm 0.04$ & 82 & 67.73 & 0.42 \\
\hline E33-31 & $5.1 \pm 0.12$ & 91 & 67.62 & 0.72 \\
\hline E33-32 & $3.08 \pm 0.002$ & $\sim 23$ & 70.14 & 0.08 \\
\hline E33-5* & $\sim 7$ & $\sim 91$ & & \\
\hline E33-13* & $\sim 6$ & $\sim 91$ & & \\
\hline E33-9* & $\sim 8$ & $\sim 99$ & & \\
\hline E33-41* & $\sim 3$ & $\sim 84$ & & \\
\hline
\end{tabular}

*Based on data from (14)

†only includes error in the isotopic measurement, does not include concentration error 


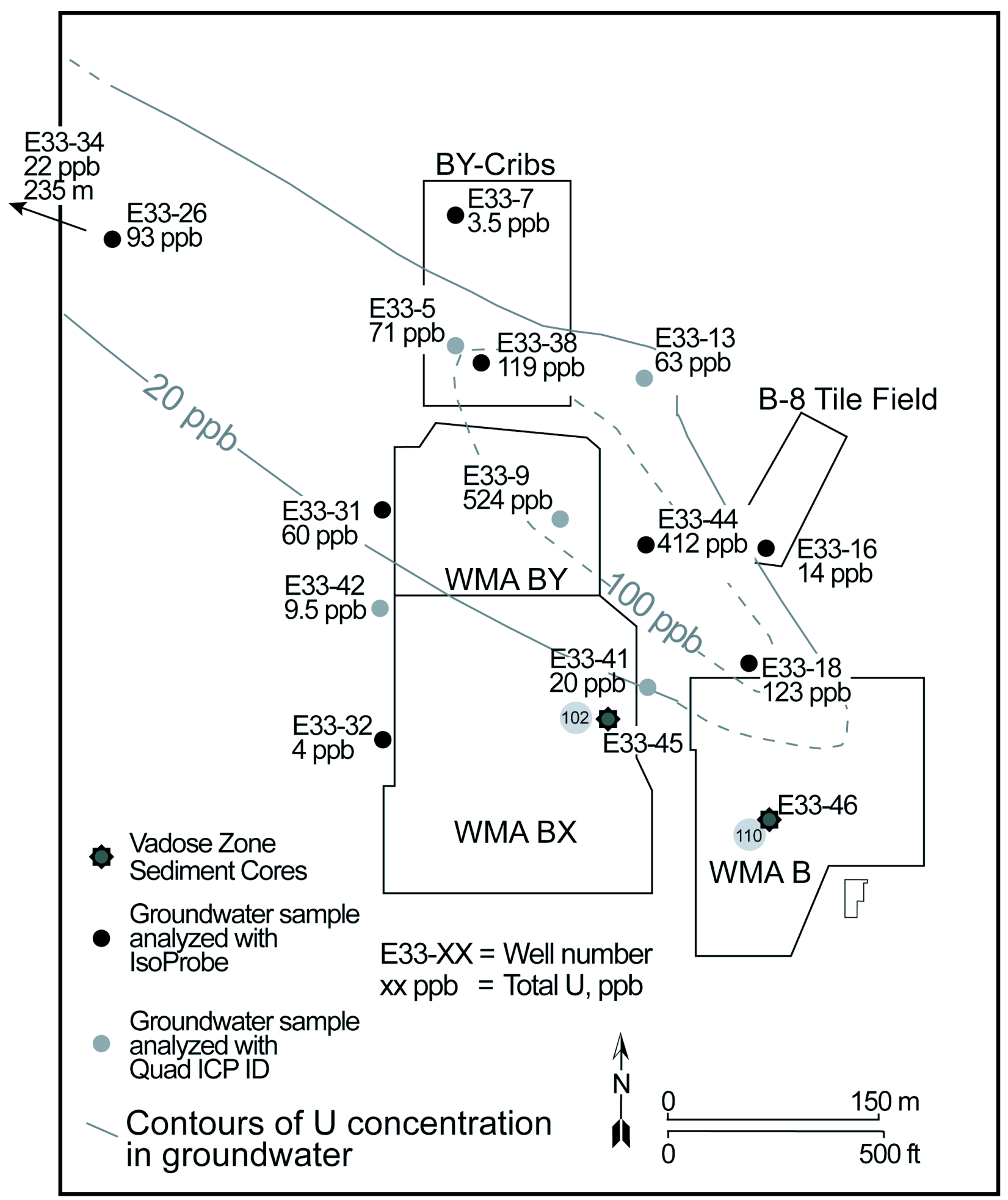

Figure 1 


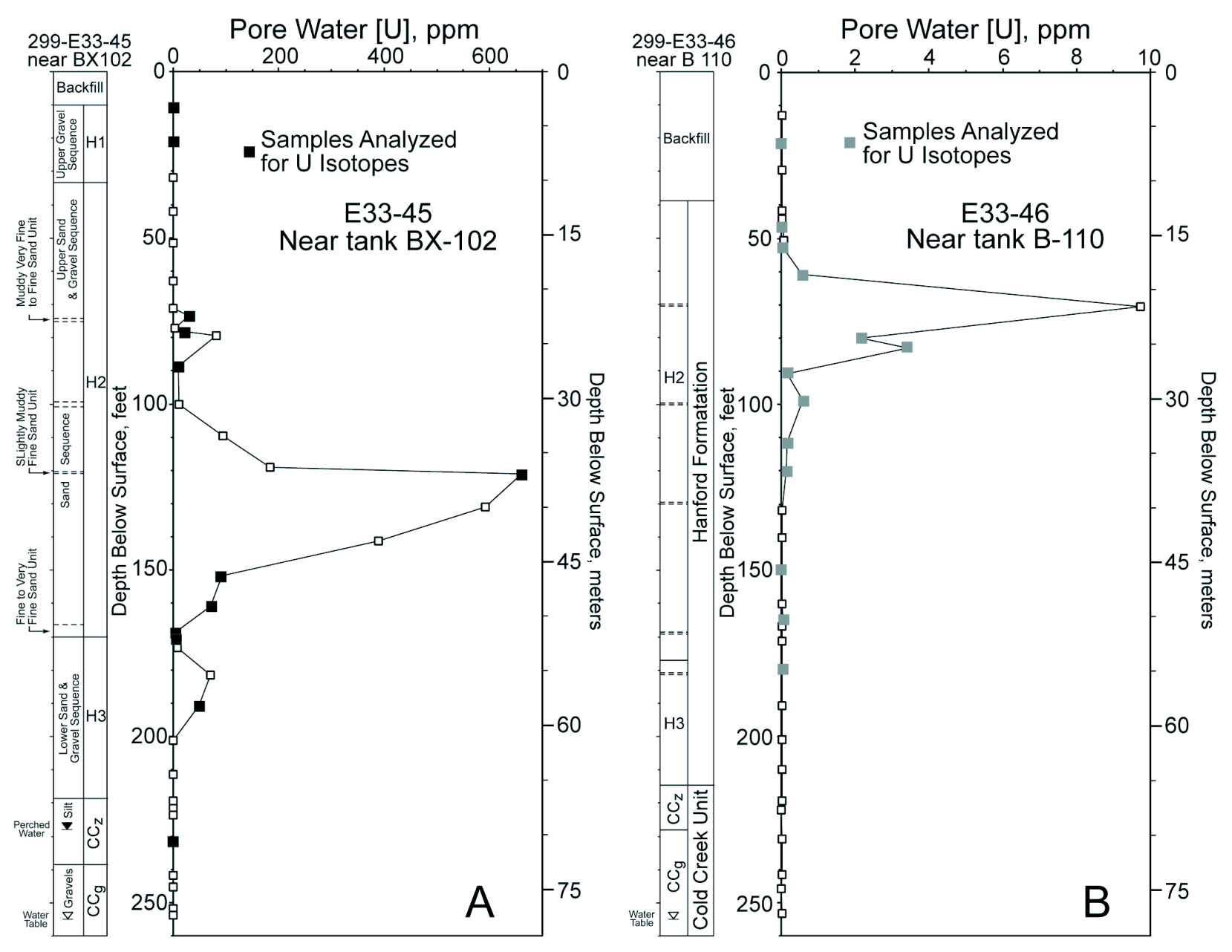

Figure 2 


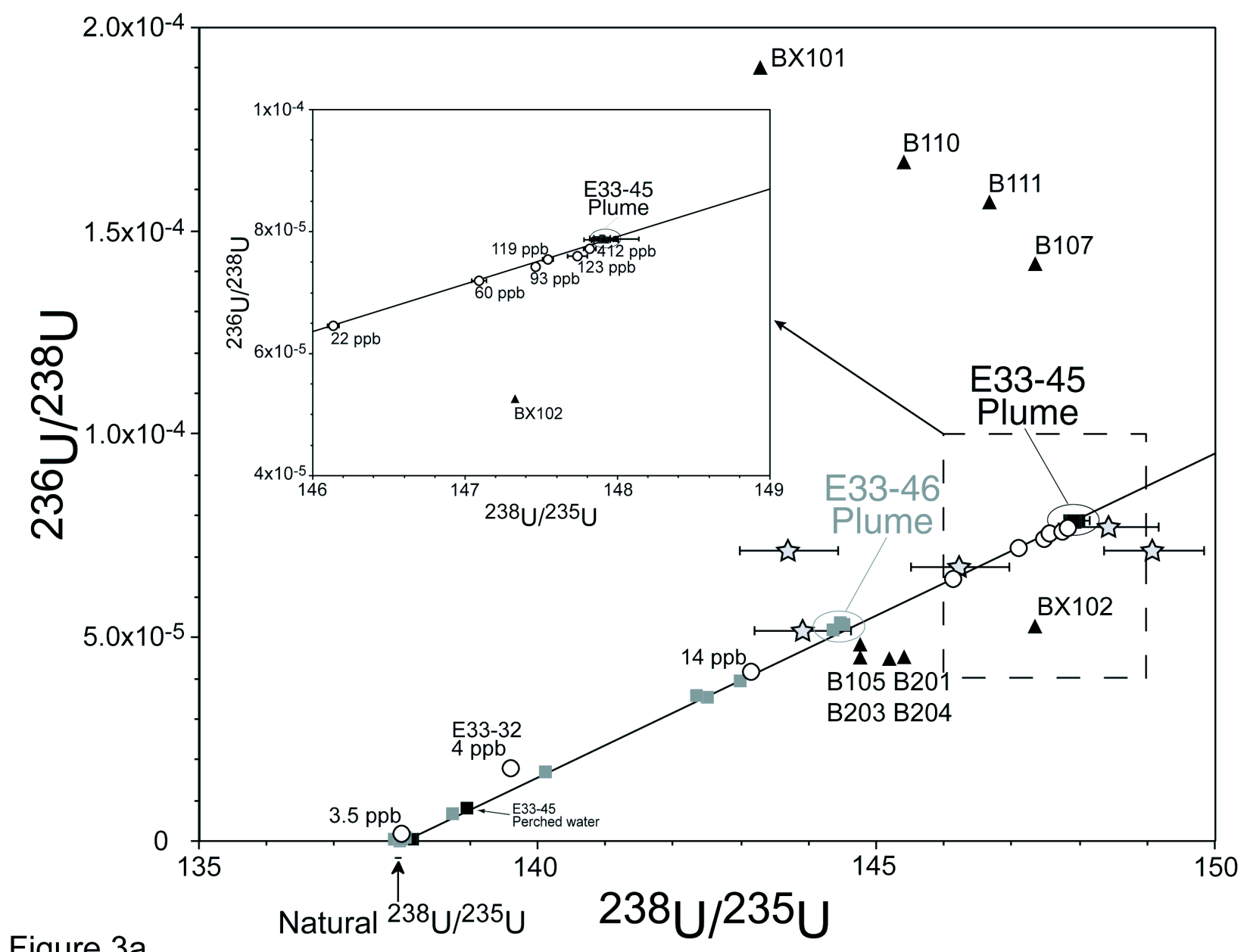

Figure $3 a$ 


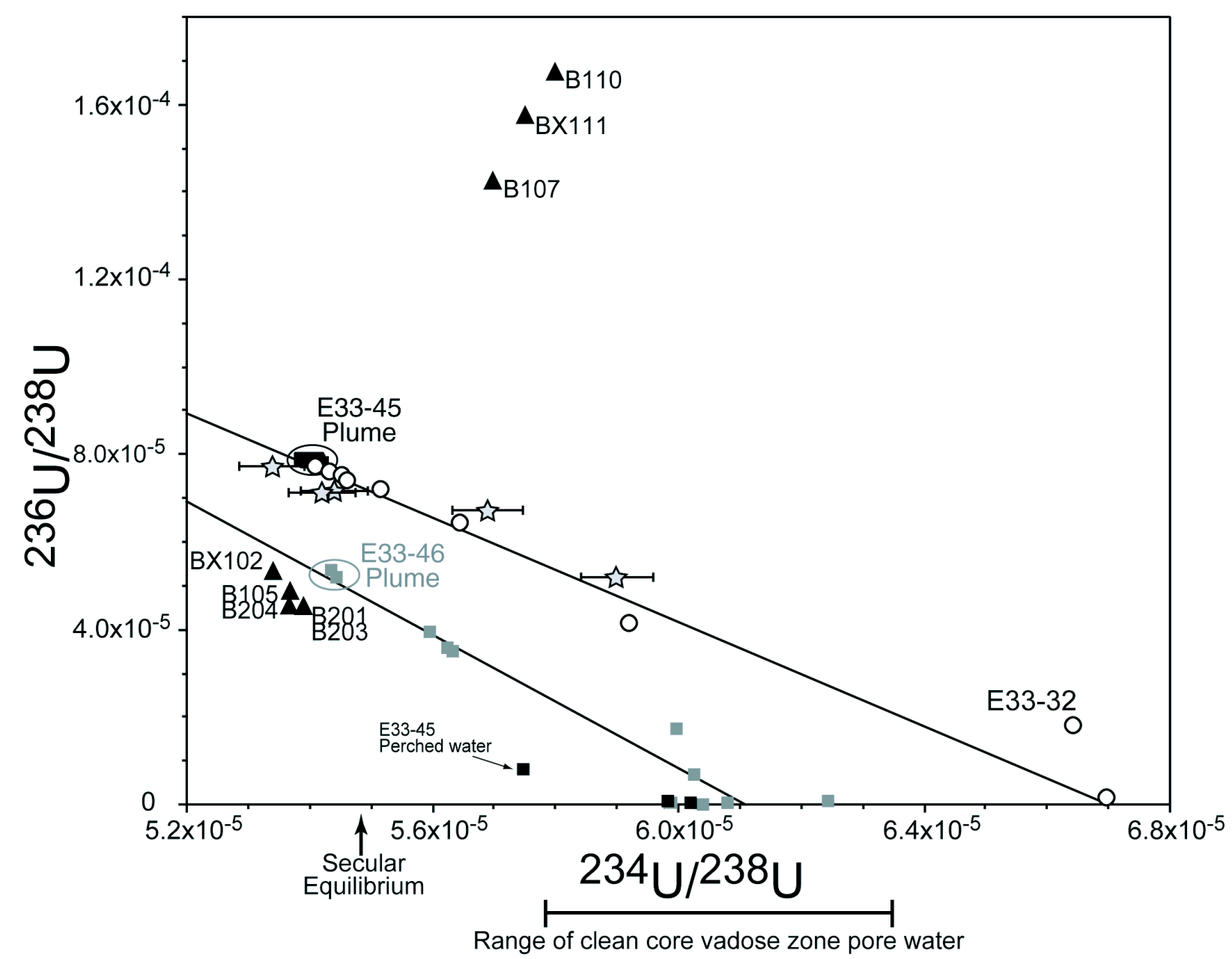

Figure $3 b$ 


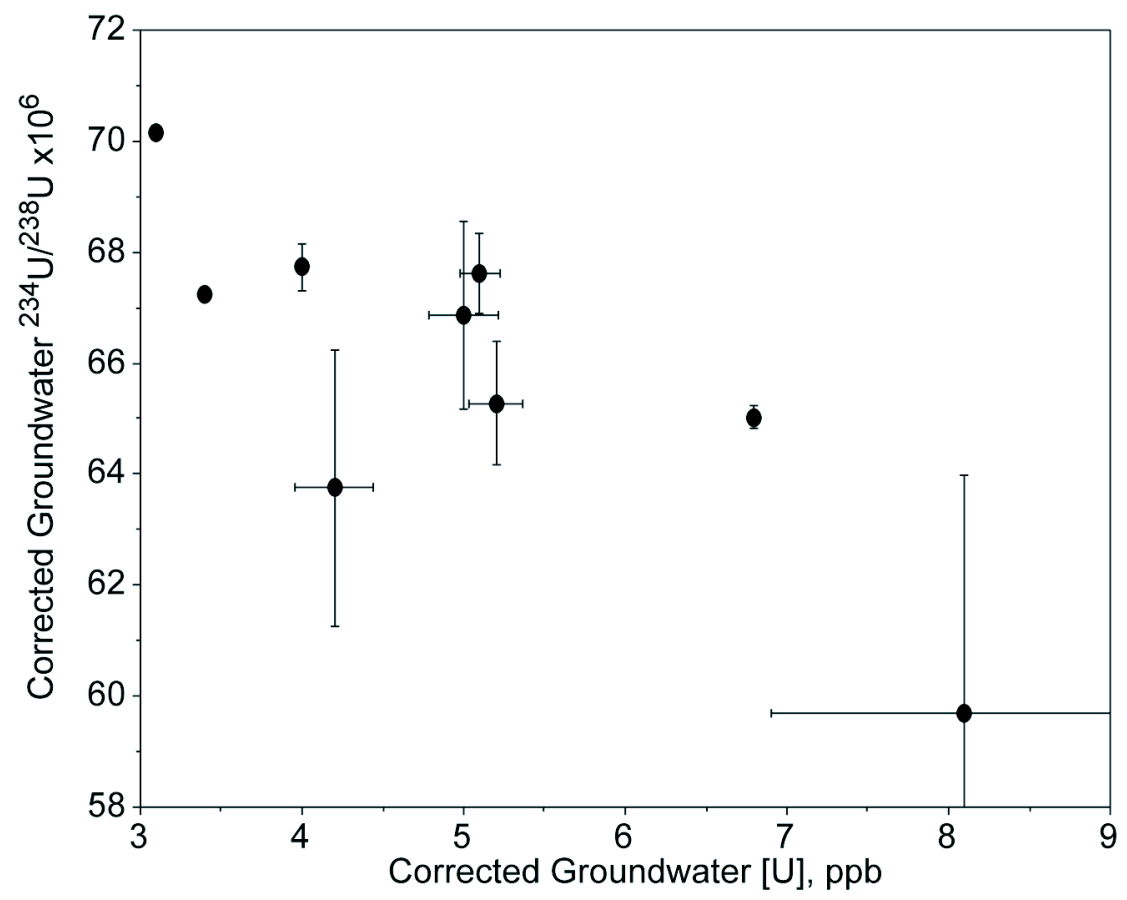

Figure 4 

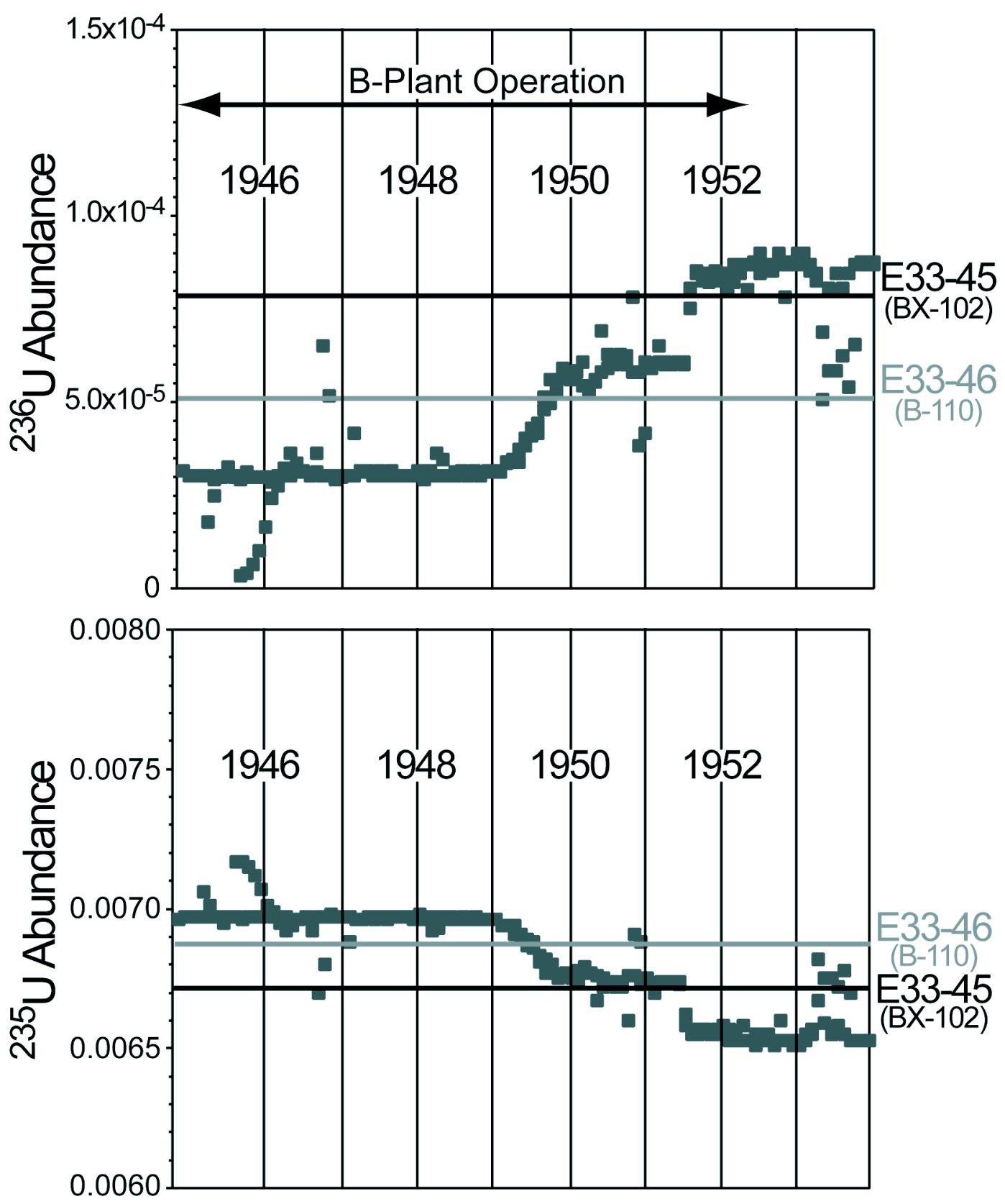

Figure 5 